$09.6 ; 14$

\title{
Разработка алгоритмов сегментации в голографической микроскопии и томографии для определения морфологических параметров клеток
}

\author{
(C) А.В. Белашов ${ }^{1}$, Д.А. Горбенко ${ }^{1,2}$, А.А. Жихорева ${ }^{1}$, Т.Н. Беляева ${ }^{3}$, Е.С. Корнилова ${ }^{3}$, \\ И.В. Семенова ${ }^{1}$, О.С. Васютинский ${ }^{1}$ \\ ${ }^{1}$ Физико-технический институт им. А.Ф. Иофффе РАН, Санкт-Петербург, Россия \\ ${ }^{2}$ Санкт-Петербургский национальный исследовательский университет \\ информационных технологий, механики и оптики (Университет ИТМО), Санкт-Петербург, Россия \\ ${ }^{3}$ Институт цитологии РАН, Санкт-Петербург, Россия \\ E-mail: belashov.andrey.93@gmail.com
}

Поступило в Редакцию 15 июля 2019г.

В окончательной редакции 24 июля 2019 г.

Принято к публикации 24 июля 2019 г.

Разработаны алгоритмы сегментации клеток на двумерных фазовых изображениях и трехмерных распределениях показателя преломления, полученных соответственно методами цифровой голографической микроскопии и томографии. Алгоритмы оптимизированы для определения морфологических параметров клеток, в том числе объема, площади проекции, площади поверхности. Проведен сравнительный анализ погрешности определения объема клеток голографическими методами с использованием разработанных алгоритмов сегментации и эталонным методом конфокальной флуоресцентной микроскопии.

Ключевые слова: голографическая микроскопия, голографическая томография, морфологические характеристики клеток, сегментация клеток.

DOI: 10.21883/PJTF.2019.22.48644.17980

На данный момент исследование многих внутриклеточных процессов проводится с помощью методов флуоресцентной микроскопии, позволяющих производить детектирование и определение области локализации многих органических соединений посредством иммунофлуоресцентного анализа [1]. Большое количество флуорофоров, специфичных к различным типам белков, участвующих в важных биологических процесcax, и быстрое развитие технологий повышения пространственного разрешения во флуоресцентной микроскопии [2] делают такие методы анализа живых клеток незаменимыми при изучении многих биологических процессов. Вместе с тем подходы, основанные на анализе морфологических характеристик клеток, попрежнему остаются актуальными и информативными как при использовании в клинической практике [3], так и в фундаментальных биологических исследованиях [4].

В настоящее время общепринятым и наиболее надежным методом определения объема, площади поверхности мембраны, индекса сферичности и некоторых других морфологических параметров клеток является конфокальная флуоресцентная микроскопия. Измерения обычно проводят с использованием флуоресцентного красителя акридинового оранжевого, который связывается с ДНК и РНК в живых клетках и интенсивно флуоресцирует при облучении в полосе 460-500 nm. Его накопление как в области мембраны, так и внутри клетки позволяет построить трехмерное внутриклеточное распределение молекул красителя и на его основе определить морфологические параметры клетки [5].
Однако необходимость введения флуорофоров в клетки и воздействие интенсивного лазерного излучения, используемого в конфокальной флуоресцентной микроскопии для их возбуждения, не позволяют проводить длительный мониторинг живых клеток [6]. В настоящей работе нами разработаны алгоритмы автоматической сегментации клеток на двумерных фазовых изображениях и трехмерных распределениях показателя преломления, полученных соответственно методами цифровой голографической микроскопии и томографии. Алгоритмы оптимизированы для определения морфологических параметров клеток.

Цифровая голографическая микроскопия позволяет восстанавливать фазовые изображения отдельных клеток и проводить их неинвазивный мониторинг в течение продолжительного времени. Определение морфологических характеристик клеток на основе их фазовых изображений может быть выполнено в предположении постоянства показателя преломления внутри клетки. Для прикрепленных клеток можно полагать, что нижняя часть поверхности мембраны клетки представляет собой плоскость с $Z=0$, а верхняя часть может быть описана уравнением

$$
Z(x, y)=\frac{\lambda}{2 \pi}\left(n_{\text {media }}-n_{\text {cell }}\right) \varphi(x, y),
$$

где средний показатель преломления клетки $n_{\text {cell }}$ считается постоянным (для фиксированных клеток $n_{\text {cell }}=1.478$ [7]), а $n_{\text {media }}-$ показатель преломления среды. Исходя из полученных данных о распределении 


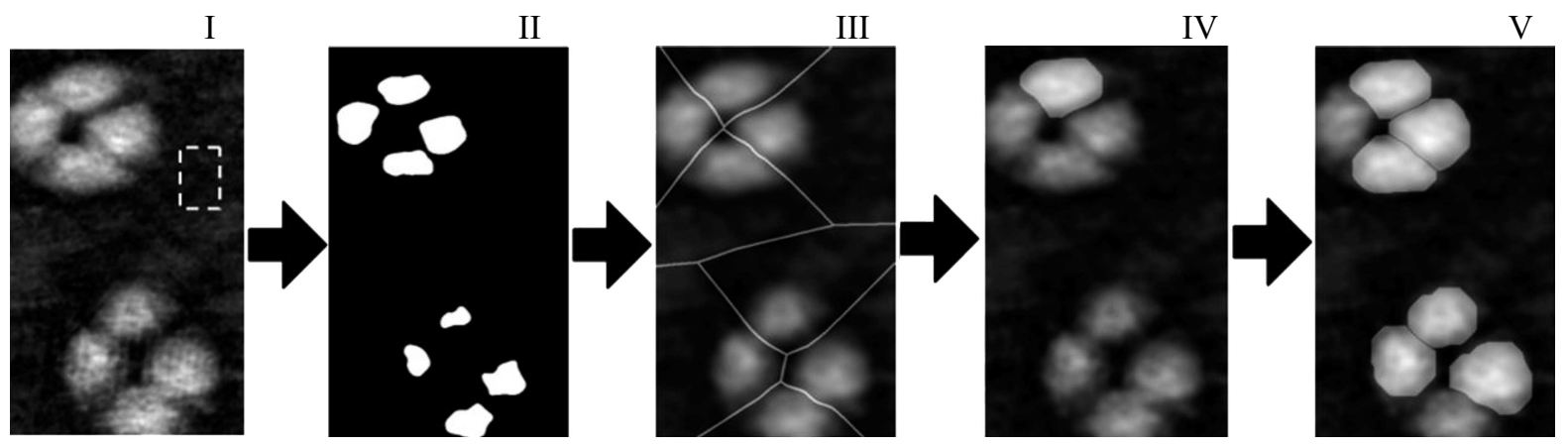

Рис. 1. Схема процесса сегментации клеток на фазовых изображениях.

фазового запаздывания $\varphi(x, y)$, внесенного клеткой в волновой фронт, могут быть определены основные морфологические параметры клетки, в том числе ее объем

$$
V_{\text {cell }}=\int_{\text {cell }} \frac{\lambda}{2 \pi}\left(n_{\text {media }}-n_{\text {cell }}\right) \varphi(x, y) d x d y
$$

и полная площадь поверхности мембраны

$$
\begin{aligned}
S_{\text {membrane }}= & \int_{\text {cell }} \sqrt{1+\frac{\partial Z(x, y)^{2}}{\partial x}+\frac{\partial Z(x, y)^{2}}{\partial y}} d x d y \\
& +\int_{\text {cell }} d x d y .
\end{aligned}
$$

Первое слагаемое в уравнении (3) представляет собой площадь верхней части поверхности мембраны, а второе слагаемое - площадь нижней, прикрепленной ее части.

Для осуществления автоматизированной сегментации клеток на фазовых изображениях, полученных в голографическом микроскопе, нами была разработана процедура, включающая пять этапов (рис. 1). Вначале (I) последовательным сканированием всего фазового изображения производится поиск области с наименьшим градиентом фазового набега, соответствующей области без клеток. Затем (II) определяется положение локальных максимумов, вокруг которых формируются маски, обозначающие примерное положение клеток. После этого (III) с использованием преобразований, описанных в работе [8], строятся разграничительные линии, разделяющие близкорасположенные клетки. Далее (IV) для определения точных границ клеток локальный максимум каждой из них расширяется с учетом разделяющих линий до тех пор, пока средний фазовый набег приращенной области не будет сравним с набегом области нормировки, найденной на первом шаге алгоритма. На последнем этапе (V) выполняется удаление клеток, соприкасающихся с границей фазового изображения.

При реализации метода голографической томографии, основанного на регистрации и восстановлении набора из нескольких десятков цифровых голограмм, зарегистрированных при различных углах падения предметной волны на исследуемый объект, может быть получен массив данных о трехмерном распределении показателя преломления в образце $[9,10]$. Важным отличием цифровой голографической томографии от традиционного метода конфокальной флуоресцентной микроскопии является то, что первый подход требует регистрации нескольких десятков цифровых голограмм, в то время как полное сканирование образца клеточных культур флуоресцентным методом требует большого числа отдельных измерений. В результате время регистрации необходимого набора данных в голографической томографии не превышает нескольких секунд, а время регистрации трехмерного распределения флуорофора в образце составляет порядка нескольких минут. Однако использование методов голографической томографии требует численной обработки полученных данных и решения обратной задачи восстановления трехмерного массива данных из набора двумерных проекций, в то время как пространственное распределение флуорофора может быть получено напрямую без дополнительных вычислений. Это приводит к значительно более простой процедуре сегментации клеток при обработке данных, полученных с использованием конфокальной флуоресцентной микроскопии [5]. Кроме того, численная обработка томографических данных зачастую приводит к искажениям в наблюдаемых массивах данных, особенно при построении изображений в сечениях $X Z$ и $Y Z$. Для повышения точности сегментации клеток на трехмерных распределениях показателя преломления нами было предложено использовать сегментацию, основанную не на показателе преломления, а на его градиенте.

Предлагаемый алгоритм работает следующим образом.

1. Исследуемая клетка приблизительно выделяется на сечениях $X Y$ и $X Z$, при этом точное определение границ клетки основывается на градиенте ее показателя преломления, что особенно важно при определении краев клетки по оси $Z$.

2. Затем включаются также те пиксели сегментируемой области, которые имеют достаточно большой показатель преломления, заведомо присущий лишь клеточным структурам. 

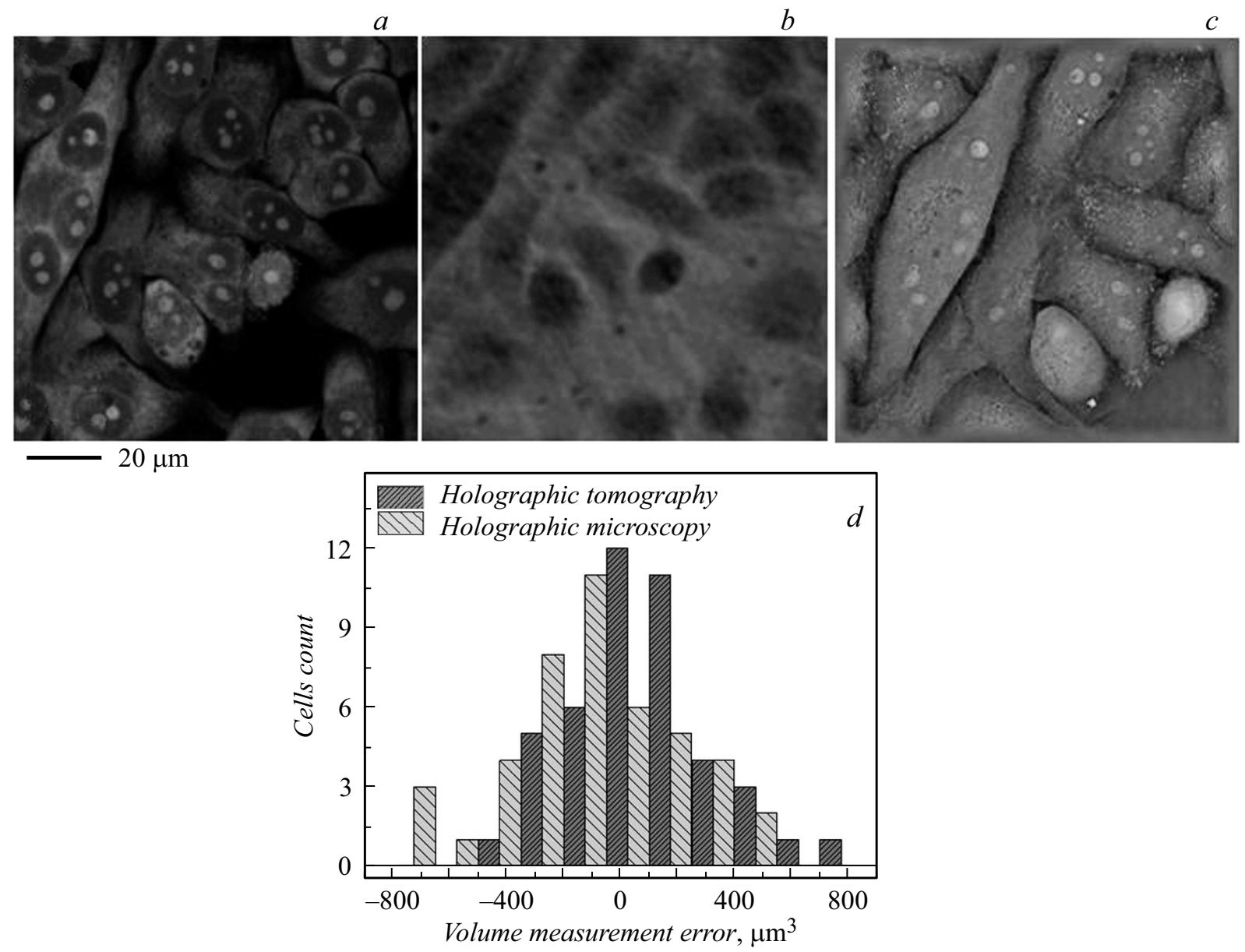

Рис. 2. Примеры изображений одной и той же группы клеток, полученных с помощью конфокальной флуоресцентной микроскопии $(a)$, цифровой голографической микроскопии $(b)$, голографической томографии $(c) . d-$ статистическое распределение ошибок определения объема клеток линии HeLa при их измерении методами голографической микроскопии и томографии.

3. Кроме того, в класс объектов, принадлежащих клетке, необходимо включить также полости, полностью или частично (на 70-80\%) окруженные сегментированными структурами. Это связано с тем, что в нормальном состоянии мембрана клетки представляет собой выпуклую оболочку.

Последний (третий) этап алгоритма может быть исключен из процесса сегментации, если проводится обработка фазовых изображений клеток с существенно искаженной морфологией, например в ходе процессов деления или некроза.

Описанные выше алгоритмы сегментации и определения объема клеток были апробированы в эксперименте, в рамках которого производилось исследование одних и тех же групп клеток в фиксированном образце клеток HeLa методами голографической микроскопии, томографии и конфокальной флуоресцентной микроскопии (рис. 2, $a-c)$. Измерения проводились на лабораторной установке голографического микроскопа (см. [4,7]), голографическом томографическом микроскопе 3D Cell Explorer (Nanolive) и конфокальном флуоресцентном микроскопе Leica TCS SP5.
Результаты определения объема клеток голографическими методами сравнивались с данными, полученными с помощью метода конфокальной флуоресцентной микроскопии, ошибка определения объема которым не превышает 5\% [5]. Полученное статистическое распределение отклонения объема клеток, измеренного голографическими методами, от результатов измерений флуоресцентным методом представлено на рис. $2, d$. Сравнительный анализ полученных результатов дает погрешность измерения объема методом голографической микроскопии $\sigma_{\mathrm{DHM}}=278 \mu \mathrm{m}^{3}$ и томографии $\sigma_{\mathrm{DHT}}=321 \mu \mathrm{m}^{3}$ при относительных погрешностях $\delta_{\mathrm{DHM}}=12.8 \%$ и $\delta_{\mathrm{DHT}}=14.3 \%$. Несколько большее значение погрешности в методе голографической томографии, вероятно, обусловлено более сложными процессами сегментации клеток в трехмерном пространстве. С другой стороны, для точного определения морфологических параметров в случае использования голографической микроскопии требуется знание среднего показателя преломления клеток, что несколько ограничивает сферу применимости данного метода. 
Таким образом, нами разработаны алгоритмы автоматической сегментации отдельных клеток на фазовых изображениях и трехмерных распределениях показателя преломления. Ошибки измерения объема клеток линии HeLa не превышали $15 \%$, что свидетельствует о том, что цифровая голографическая микроскопия и томография могут быть успешно использованы для определения морфологических характеристик клеток. Существенными достоинствами голографических методов являются неинвазивность и возможность длительного наблюдения изменений живых клеток в динамике.

\section{Финансирование работы}

А.В. Белашов благодарит Совет по грантам Президента РФ за финансовую поддержку (проект СП-2349.2019.4).

\section{Конфликт интересов}

Авторы заявляют, что у них нет конфликта интересов.

\section{Список литературы}

[1] Hu Y., Murphy R.F. // J. Immunolog. Meth. 2004. V. 290. N 1-2. P. 93-105.

[2] Huang B., Bates M., Zhuang X. //Annu. Rev. Biochem. 2009. V. 8. N 1. P. 993-1016.

[3] Sherwin T., Brookes N.H. // Clin. Exp. Ophthalmol. 2004. V. 32. N 2. P. 211-217.

[4] Zhikhoreva A.A., Belashov A.V., Bespalov V.G., Semenov A.L., Semenova I.V., Tochilnikov G.V., Zhilinskaya N.T., Vasyutinskii O.S. // Biomed. Opt. Express. 2018. V. 9. N 11. P. 5817-5827.

[5] Blatter L.A. // Meth. Enzymology. 1999. V. 307. P. 274-295.

[6] Icha J., Weber M., Waters J.C., Norden C. // BioEssays. 2017. V. 39. N 8. P. 1700003.

[7] Belashov A.V., Zhikhoreva A.A., Bespalov V.G., Novik V.I., Zhilinskaya N.T., Semenova I.V., Vasyutinskii O.S. // J. Opt. Soc. Am. B. 2017. V. 34. N 12. P. 2538-2543.

[8] Meyer F. // Signal Process. 1994. V. 38. P. 113-125.

[9] Belashov A.V., Petrov N.V., Semenova I.V. // Appl. Opt. 2016. V. 55. N 1. P. 81-88.

[10] Kujawińska M., Krauze W., Baczewska M., Kuś A., Ziemczonok M. // Quantitative Phase Imaging V. 2019. V. 10887. P. 1088708. 